At one time, all the apertures for the entrance and exit of air from the lying-in room were carefully stopped up, on the idea of the patient being now especially liable to suffer from cold; bed-clothes were heaped on, and at one time spiced cordials were diligently given. Now we take pains to ventilate the room well; but, while we do not keep off the access of cool air, we are very apt, if we keep to another part of the old system, to have our patient in a very unfit state to bear the air. For a constant course of gruel in vast quantities and tea relax all the tissues, and the skin among the rest. The female acquires, after a time, a perfectly sodden appearance, which is quite characteristic. The flesh pale and soft and moist; the abdomen full of flatus.

But we are told that such a diet is good for the flow of milk. In the early period of lactation, however, there is likely to be too much rather than too little milk; and, with regard to the quality of that milk, if we compare it with other secretions, we must suppose that it will be most perfect in its character, and so most suitable to build up the child, when the general health of the mother is in its most perfect state. And here I would say a word of milk-fever, which perhaps I ought to have mentioned before. We read much of it; but I believe that, except in primiparæ, the secretion of milk commences without any febrile phenomena whatever, and in the case of primiparæ, I have already explained that other causes lead us to adopt a rather more severe regimen than in other cases.

The whole subject of diet is so extensive, for it must be adapted to the season, the constitution, and the habits of life, that I shall be excused if I have only on this occasion dipped a little into the matter; and I shall be glad to know from those who have a more extended experience in midwifery, what line of practice they adopt; and whether there are any who still adhere to the rigid rules that we seem to have learnt rather from Celsus, or some of his predecessors, than from Nature.

ON THE DIFFERENT FORMS OF HAMORRHAGE WITHIN THE EYE, PRODUCED BY INJURY.

By George Lawson, F.R.C.S., Assistant-Surgeon to the Royal London Ophthalmic Hospital, Moorfields, and the Middlesex Hospital.

$$
\text { [Continued from p. 584.] }
$$

Deep or Posterior Traumatic Homorrhage, as it is commonly called to distinguish it from the hæmorrhage of the more superficial structures into the part of the eye anterior to the lens, may occur-

1. Between the choroid and retina ;

2. Between the choroid and sclerotic.

In the first, the retina is separated by the clot from the choroid; whilst in the second the choroid is detached from the sclerotic. Both forms may, however, be present in the same eye, when the hæmorrhage is caused by great violence.

3. Hæmorrhage may take place into the vitreous body.

In considering the first two forms of hæmorrhage, it is a fact of pathological interest to notice, that, though both may and often do occur together in the same eye after a severe injury, yet there are special circumstances which may cause the one kind of hæmorrhage to predominate over the other, and even the one to take place independently of the other. It must, however, be remembered that, in many cases of rupture of the globe, in which posterior hæmorrhage almost invariably occurs, the primary injury is so serere that all the vascular tissues

$$
604
$$

of the eye are inclnded in it, and hæmorrhage from each at once ensues.

1. Homorrhage between the Choroid and Retina. This may take place either with or without rupture of the external tunics of the eye. It is generally caused by blows with the fist or from some large foreign body, or by striking the eye in a fall against a projecting object. The effusion of blood may be limited to a small clot, or it may be so extensive as at once to entirely destroy the eye for all visual purposes. The severity of the injury is very greatly increased when it is accompanied with a rupture of the sclerotic or cornea. Having had frequent opportunities of examining eyes which had been removed on account of their complete loss from deep intraocular hæmorrhage induced by injury, and in many cases accompanied with rupture, more or less extensive, of their external coats, I have noticed that the seat of hoomorrhage is influenced by the nature of the injury, and by the soundness of the eye at the time of its infliction.

a. When deep posterior hæmorrhage is due to a blow on a previously healthy eye, the external coats of the eye not having been ruptured, I have generally found that the principal hæmorrhage is between the choroid and retina. The blood has been effused from the anterior surface of the choroid, and has caused a separation of the retina from it, in some cases only partially, in others to its entire extent, from the entrance of the optic nerve as far forwards as the ora serrata. In the severe cases, there may be some hæmorrhage between the choroid and sclerotic, and small scattered clots may be seen; but, as a rule, this is not its chief seat, for the principal effusion is between the choroid and the retina. In occasional cases, instead of the retina being much detached from the choroid when hæmorrhage takes place between these structures, the blood bursts its way through the retina, and, if only small in quantity, forms a clot which will often at first appear as if it were lying on the retina; or, if the bleeding be more extensive, it may force its way through the hyaloid, and become extravasated into the vitreous body. The following case is an example of a limited hæmorrhage between the choroid and retina. The structure of the retina had been torn through; and the remains of, and the site occupied by, the blood-clot, were still easily seen by the ophthalmoscope ten months after the receipt of the injury.

CASE I. Blow on the Eye Ten Montihs previously: Limited Homorrhage between the Choroid and Retina: Rent of the Retina immediately in Front of the Clot. Wm. R., aged 39, a sailor, came to the hospital from Sunderland on July 12th, 1865. He stated that, ten months ago, he had received an injury to the right eye. One day, whilst on board ship, his foot slipped, and in his full he struck the right eye against one of the stancheons of the ship. The eye had now recovered from the injury, but his sight was very much impaired. In the immediate axis of vision, he was blind; but by turning the eye either way, so as to look laterally, he was able to read letters of No. 16 of Jïger. When he looked straight at an object, he was unable to see it; but he could discern bodies on either side of it. On examination with the ophthalmoscope, the cause of his defect of sight was manifest. In the immediate neighbourbood of the yellow spot, and almost in the axis of vision, there was seen a small rent in the retina, the edges of which could be distinctly made out; and lying upon what now represented the choroid in this site was a black deposit, evidently either the remains of a blood-clot with some pigment, or else a deposition of pigment, which had taken place either during or since the absorption of the clot. 
In many instances, where hæmorrhage between the choroid and retina has followed as the result of an accident, and the structures in the front of the eye are still clear, and not masked by any anterior bleeding, a diagnosis of the extent of the injury and of the seat of the hrmorrhage may be made with the ophthalmoscope. The red clot may be seen at the fundus of the eye, bulging forward the retina; and oftentimes a careful examination will detect the retinal vessels running over its surface.

CASE II. Limited Homorrhage between the Choroid and Retina, from a Blow with a Piece of a Rivet; the Blood-clot being clearly seen by the Ophthalmoscope a few Hours after the Accident. James R., a boilermaker, came to the hospital on September 9th, 1865, on account of an injury he had that morning received to the right eye. Whilst engaged in striking a bolt, a piece of iron flew off and struck his right eye. On the nasal side of the cornea there was considerable ecchymosis of the conjunctiva. The pupil was slightly more dilated than that in the other eye, but, within a limited range, acted sharply. A portion of the field of vision on the outer side was quite destroyed. The anterior chamber and the humours of the eye were clear. Examined with the oph. thalmoscope, a blood-clot was seen at the upper and inner part of the eye, behind the lens, and bulging into the vitreous body. Another smaller clot was also seen on the same side, but nearer the fundus of the eye. The hæmorrhage was probably between the choroid and the retina, bulging the retina forwards. The ontline of the clots was evenly defined.

This man continued for nearly five weeks under treatment. When last seen, the ecchymosis of the conjunctiva had quite disappeared, and all the blood within the eye had been absorbed; but the sight had in no way improved. There was a detachment of the retina on the inner side; and the outer part of the field of vision was quite destroyed.

$b$. Deep posterior hcemorrhage is often associated with rupture of the external coats of the eye; the injury being frequently so severe as to cause at the same time a loss of the lens or a portion of vitreous body, or perhaps of both. If the injury have been inflicted by a blunt or semi-blunt instrument, so that the external coats have not been cut, but ruptured by the force of the blow, and the eye have been previously healthy, the chief seat of the hæmorrhage will generally be found to be between the choroid and retina, although some small extravasations of blood will probably also have taken place between the choroid and sclerotic. As, in such injuries, an escape of more or less vitreous usually occurs, it is an interesting question to decide whether the hæmorrhage between the choroid and retina is due to a direct rupture of the choroidal vessels from the blow, or whether a primary separation of the retina from the choroid may have been occasioned by the sudden loss of vitreous, the hæmorrhage being consequent on, but secondary to, this detachment. I believe that, in nearly every case, it will be found that the hæmorrhage is due solelv to a direct rupture of the choroidal vessels; and that the separation of the retina is brought about by the blood being poured ont between it and the choroin.

In examining carefully into the history of these cases, we find that though, in many of the ejes which had been ruptured, the lens and a certain amount of vitreous had escaped through the wound, yet that the loss of vitreous was small at the time of the accident, and certainly not sufficient in a healthy eye to produce a detachment of the retina. In some of the cases of ruptured eyes which have come under my care, $I$ am sure that the great bulk of the vitreous which had been lost did not happen at the time of the infliction of the injury; but it had drained away afterwards from the pressure of the increasing bloodclot behind the retina, squeezing it out of the eye as it occupied itself the vitreous space.

The following is a very interesting case of traumatic hæmorrhage occurring first between the choroid and retina, and afterwards between the choroid and sclerotic in the same eye, but at different times and under different circumstances.

The eve, at the time of the original injury, was healthy; and hæmorrhage undoubtedly occurred between the choroid and the retina from a direct rupture of the anterior choroidal vessels. Nine months after the injury, the patient came under my care. The eye was then quite blind, with a large ciliary staphyloma, and excessively painful. I excised the eye; and, during the operation, the staphylomatous portion of the globe either gave way or was accidentally pricked by the scissors, and some fluid vitreous at once escaped. On examining the eye afterwards, an old blood-clot was seen between the choroid and retina; but recent hæmorrhage had taken place during the operation between the choroid and sclerotic, caused by the sudden withdrawal of vitreous from an eye in an unsound state.

CASE III. Homorrhage between the Choroid and Retina from a Blow: Excision of the Eye Nine Months after the Injury: Rupture of the Staphylomatous Portion of the Globe during the Operation: Escape of Vitreous, and immediate Hamorrhage between the Choroid and Sclerotic. Susannah W.. aged 40, was admitted into the hospital on May 22nd, 1865 . She stated that, at the beginning of last September, she accidentally ran in the dark against the door, striking, she thought, the left temple, and inflicting a wound close to the outer edge of the orbit. For the first two months after the injury, she did not appear to have suffered very much pain. Since last January, she had suffered from pain in that eye, and during the last three months it had at times been very intense. It was on account of the pain that she came to the hospital, as the eye was quite blind.

Present State. The shape of the eye was altered in form. Along the upper portion of the ciliary region, behind the upper margin of the cornea, but in front of the insertion of the superior rectus muscle, was a large staphylomatous bulge, which had to the touch a sense of solidity. It extended laterally almost as far as the upper edge of the insertions of the external and internal recti muscles. The eye was quite blind; and the bulging, she said, was rapidly increasing. I recommended the removal of the eye; and she at once consented, on ar:count of the great pain from which she was then suffering. During the operation, the staphylomatous portion of the eye was either pricked by the point of the scissors, or from some other accidental cause it gave way, and a portion of the semifluid vitreous escaped.

On examining the eye after its removal, the great bulging of the upper part of the ciliary region was seen to be entirely due to a deposition of lymph, nearly three-eighths of an inch in depth, at the most prominent part. It appeared as if the sclerotic had been ruptured, but perhaps not throughout the entire thickness of its structure; and that the film of tissue which had held externally its edges together had yielded before the pressure from within, and become staphylomatous ; but that, as it bulged, lymph had been effused, which increased in quantity as the staphyloma increased in size.

On making a section of the eye, the retina was seen detached from the choroid throughout its entire extent by the remains of an old blood-clot; and the choroid was completely separated from the sclerotic by fuid and evidently recently effused blood. It was clear that the hemorrhage between the choroid

605 
and sclerotic had taken place during the operation, and was consequent on the giving way of the staphylomatous bulge and the sudden escape of vitreous in an unhealthy eye. The vitreous which remained was semifluid.

[To be continued.]

\section{Cramsactions of 遂ramethes.}

\section{WEST SOMERSET BRANCH.}

ON DROPSY AFTER SCARLATINA.

By William Legge, Esq., Wiveliscombe.

[Read October 4 th, 1865.]

I Do not claim for the few observations I propose making this evening any originality, nor do I pretend to suggest anything novel, either in theory or practice, with regard to the treatment of a disease with which we are all so familiar as dropsy occurring after scarlatina; but I desire to elicit, by a discussion of the subject, the results of our individual ex. perience, believing that the main object of our meetings will be thus atiained, and our mutual advance in successful practice materially assisted.

At a former meeting of our Branch, when I ventured to draw attention to the treatment of scarlatina, I only cursorily alluded to the frequency of dropsy as a sequel of the disease. Since that time, I have had under my care one hundred and thirtren additional cases, making a total of one hundred and ninetythree, the results of which, while they served to confirm the conclusions then deduced, and to illusstrate the necessity for the application of rational principles as opposed to mere routine practice in dealing with the various abnormal symptoms presented during the progress of the disorder, tended also to impress one with the grave significance of anasarca, that most frequent and fatal of the sequelæ of the disease. The results of $\mathrm{my}$ own experience showed that of 193 cases of scarlatina, 78, or just 40 per cent., suffered from dropsy afterwards, of whom 7 per cent. died; whilst the mortality from all causes was 14 per cent., thus exhibiting the fact that half the fatal cases were the result of dropsy.

I shall not occupy your time by the narration of individual cases, but shall briefly state the inferences derived from gencral results.

Dr. Watson, in his valuable Lectures, attributes this frequent occurrence of anasarca as a sequel of scarlatina (as also the fact of its being more common after a mild than after a severe attack) to the circumstances that, "less care and caution are observed in milder cases during the dangerous period of desquamation and convalescence." This explanation doubtless holds good to a certain extent; but how are we to account for the numerous cases of dropsy supervening in patients who have never incurred the danger of a check to the escape of the fever-poison through the outlet afforded by the skin-patients who have never left the sick room before the presence of anasarca has been recognised ?

The answer to this question, and at the same time a reasonable explanation of the morbid phenomena, I first heard suggested by Dr. Basham, when attending his lectures, to the effect that in mild scarlatina the fever-poison is not all eliminated from the system during the eruptive stage, and therefore such an attack is more likely to be followed by dropsy. Dr. Basham has since discussed this pathological question, and the cause of impeded circulation in the 606 kidney with consequent non-elimination, in his interesting work On Dropsy Connected with Disease of the Kidneys. He there states that, "in the vast majority of cases, this secondary condition must be accepted as evidence of the imperfect elimination of the febrile poison during the antecedent exanthematous stage, arising either from the greater intensity of the poison, or the incompleteness of the processes by which it is released from or decomposed in the system." The same considerations have evidently led to the opinion which Dr. Hughes Bennett expresses in his Lectures, that the head symptoms so often accompanying severe cases of scarlatina probably depend, not so much upon inflammation of the brain as upon non-elimination and consequent absorption of, and poisoning by, urea, as manifested by the diminished quantity of the renal secretion, and its freedom from deposit.

Dr. Bennett's views as to resolution by cell-growth, are illustrated by these explanations of the cause of certain symptoms during the excretion of noxious matters from the economy; for the presence of degraded cells in the urinary deposit, as seen under the microscope, is a constant sign of progressive mischief.

It is unnecessary to enter minutely into all the symptoms of this form of renal disease; its evidently inflammatory origin has caused it to be assigned to the class of febrile dropsies ; rigors, headache, pain, and tenderness in the region of the kidneys, all give evidence of a secondary febrile attack; the face and eyelids become puffy, general anasarca follows, and effusion of fluid into one or more of the serous cavities may ensue. The appearance of the urine soon indicates renal mischief; hæmaturia to a greater or less extent, from a mere smoky dusky colour, to a deep blood-red, is often present. As a general rule, the urine is highly albuminous, but this is not invariable. In more than one case I found albumen present at the first examination, and absent a day or two after. It is this non-persistent coagulability of the urine in conjunction with deposits of urates, etc., which Dr. Bennett considers evidence of the excretion of morbid products which have circulated in the blood.

Too much importance cannot be attached to the examination of the renal secretion (which is indeed the only safe method of insuring a correct prognosis). The microscopic appearances are very characteristic, and we may safely assert that the recent great advances in renal pathology, and consequently in the successful treatment of renal mischief, are mainly due to the revelations of the microscope, which is of even greater assistance in the diagnosis of kidneydiseases, than the stethoscope in pulmonary affections; for by the unassisted ear the chest may be satisfactorily auscultated, whilst to unaided vision the secrets lying hidden in the renal secretion must for ever remain undiscovered. The examination of the urinary sediment will demonstrate the presence of casts of the uriniferous tubes, epithelial cells, bloodcorpuscles, fibrinous blood-casts, and other indications of renal degeneration. Dr. Basham teaches that, as long as the epithelial cells remain unchanged, a favourable termination may be expected; but that "the foretoken of danger is the appearance of degraded or atrophic cells." As illustrative of this, I may instance the case of a child aged 7 years, who after a mild attack of scarlet fever, began to present the ordinary symptoms of dropsy. He had hæmaturia; the urine was diminished in quantity, specific gravity 1012 , and albuminous; under the microscope bloodcasts were evident, as well as free blood-corpuscles and scattered epithelial cells. On the fourth day, he was seized with violent convulsions and delirium, 